\title{
Artificial Neural Network Prediction of Viscosity Index and Pour Point of Some Bio Lubricants from Selected Oil Plants
}

\author{
A.A. Onogu \\ Physical Planning Department, \\ Kogi State University, Anyigba, \\ Kogi State, Nigeria
}

\author{
M.I. Oseni \\ Mechanical Engineering \\ Department, University of \\ Agriculture, Makurdi, Benue \\ State, Nigeria
}

\author{
A. Ashwe \\ Mechanical Engineering \\ Department, University of \\ Agriculture, Makurdi, Benue \\ State, Nigeria
}

\begin{abstract}
Artificial neural network as a modeling tool was utilized in predicting Viscosity index and Pour point of some bio lubricants from selected bio plants. In the laboratory the bio lubricant were extracted by Soxhlet processes and blended with additives from botanical plants after which their characterization were carried out.

The neural model of Viscosity index and Pour point was developed based on parameters from Products extraction \{Three (3) parameters\}, Products blending \{Four (4) parameters\}, Products characterization \{Two (2) parameters\}. The nine (9) parameters were used as inputs into the network architecture of $9(5)_{1} 2$ in predicting the Viscosity index and Pour point, after series of network architectures were trained using different training algorithm such as LevenbergMarquardt, Bayesian regulation, Resilient back propagation etc. Using MATLAB 7.9.0 (r20096), the prediction of the neural network exhibited reasonable correlation with the targeted (real) Viscosity index and Pour point and predicted Viscosity index and Pour point with the network errors being reasonable.
\end{abstract}

\section{General Terms}

Bio lubricants characteristics and their chemo physical properties

\section{Keywords}

Artificial neural network, Bio lubricants, Oil plants, Viscosity index, and Pour point

\section{INTRODUCTION}

Lubricant is a substance (often liquid) introduced between two moving surfaces to reduce the friction between them, improving efficiency and reducing wear. Lubricants dissolve or transport foreign particles and distribute heat. The additive present in lubricant help to deliver reduced friction and wear, increase viscosity, improved viscosity index, resistance to corrosion and oxidation, contamination etc [1]

Lubricants are of different types namely mineral, synthetic and bio based. Mineral based lubricants and additives may not adequately satisfy the global growing demand for lubricants, since crude oil depletion, toxicity and non degradability as well as rising price has become a global concern. This creates a need for a better alternative source of lubricant and additive by use of oil plants. The products obtained from these oil plant referred to a bio-based products are suitable for formulating greases, engine oils, hydraulic, and transmission fluids, required by machines [2].

The bio base stock and bio additives selected were obtained from the following listed below: - Jatropha seeds (Jatropa curcas), Palm kernel nuts (Elacis guineansis), Soybean seeds, (Glycine soja), Yellow oleander seeds (Nerium oleander), and Groundnuts seeds (Arachis hypogeal) for bio lubricant base stock. Moringa tree barks (Moringa oleifera) Jatropha stems (Jatropha curcas); Cocoyam stems (Colocasia esculenta). Yellow oleander latex (Nerium oleander) and African elemi tree barks (Canarium schweinfurthii) were used for bio base additives.

The system adopted for the use of the above mentioned materials were as follows:-

-Selection of some oil seed crops and botanical plants.

-Soxhlet process extraction of products from selected oil seed crops and botanical plants.

-Blending of bio additive with bio base stock.

-Characterization of the bio products. All these activities were carried out in the laboratory and useful data generated from the series of experiments carried out.

The interest in artificial neural network (ANN) modeling in fields of engineering has increased rapidly. For instance, [3] investigated analysis of the effect of reinforcement particles on compressibility of AI -SIC composite powders, [4] studied prediction of corrosion rate of magnesium-rare earth alloys, and [5] investigated prediction of corrosion behavior of alloy 22 using neural network as a data mining tool. Artificial neural network corrosion modeling for metals in an equatorial climate was studied by [6]. While the neural network methods for corrosion data reduction was carried out by [7]. Artificial neural network usage in predicting erosive wear was also investigated by [8], [9] studied wear volume prediction with artificial neural network.

This paper intends to use artificial neural network in predicting the Viscosity index and Pour point of some bio lubricants from selected bio plants. The neural model of the prediction of Viscosity index and Pour point was obtained from the functional approximation between the following inputs: - Material selection and extraction, material blending, material characterization processes versus Viscosity index and Pour point as output. 


\section{MATERIALS AND METHODS}

\subsection{Material}

The required samples for these studies were obtained from Anyigba Kogi State, Nigeria. The latex were collected from cuts on fresh barks of Yellow oleander plant and preserved in properly sealed container kept at room temperature. These seeds and stem samples obtained were dried at room temperature for proper dehydration. Foreign particles like stones and other impurities were removed and the stems were cleaned before ground into powder as to obtain higher purity.

The dried samples were pounded in the mortar with pestle to reduce their sizes and later ground into powder in a grinding machine. The powder samples were measured into quantities of 100grams using an analytical beam balance. For identification purposes, the samples were coded before they were subjected to further required laboratory processes. Gravimetric and chemo-physical analysis on the samples was carried out in Nigerian Institute of Laboratory Technology, Ibadan Oyo State Nigeria. These experimental processes ranged from extraction, blending, and characterization.

\subsection{Neural Network Modeling}

The development of a neural network for prediction of Viscosity index and Pour point was based on experimental data. The experiment was carefully planned to provide the input/output quantities for the neural networks training validation and testing. To obtain this model the following steps were adopted

Data generation, (ii) Definition of the ranges and distribution of the training data set, (iii) Data pre processing, (iv) Selection of neural network architecture, (v) Selection of training algorithms, (vi) Training the neural network, (vii) Testing or predicting the artificial neural networks.

\subsection{Input Data}

The input data were generated from extraction, blending and characterization processes, with Viscosity index and Pour point as outputs. The total numbers of input parameters in the artificial neural network were nine (9). Extraction processes were represented by three (3) parameters, namely: (i) Bio base stock (ii) Bio additive (iii) Extraction temperature. Blending process was represented by four (4) parameters namely:- (i) Density (ii) Flash point (iii) Viscosity at $40{ }^{\circ} \mathrm{C}$ (iv)Viscosity at $100{ }^{\circ} \mathrm{C}$ and Characterization process were represented by two (2) parameters namely:(i) Characterization temperature and (ii) Characterization time.

The input parameters numbers were identified and their ranges also specified. These inputs data relating to the processes are shown in Table 1 below.

Input data ZT1-ZT10 were used for training the network while ZP1 -ZP5 were employed for testing the prediction capabilities of the artificial neural network. The values of data for training the neural network was chosen outside or within the values of ZP1- ZP5 obtained experimentally.

The data for the neural network prediction were obtained from the five (5) samples of blended bio lubricants produced from the blend of bio additive with bio base stock as in Table 1 below.

The working together of the influence of these (9) inputs parameters on Viscosity index and Pour point are illustrated in figure 1.

Table 1: Set of Input Parameters used for training and

$$
\text { Testing }
$$

\begin{tabular}{|c|c|c|c|c|c|c|}
\hline $\begin{array}{l}\text { Parameter } \\
\text { s }\end{array}$ & $\begin{array}{l}\text { Trai } \\
\text { ning } \\
\text { data } \\
\text { set } \\
\mathrm{Z}_{\mathrm{T}^{-}} \\
\mathrm{Z}_{\mathrm{T} 10}\end{array}$ & $\begin{array}{l}\text { Test } \\
\text { data } \\
\mathbf{Z}_{\mathbf{P 1}}\end{array}$ & $\begin{array}{l}\text { Test } \\
\text { data } \\
\mathbf{Z}_{\mathbf{P 2}}\end{array}$ & $\begin{array}{l}\text { Test } \\
\text { data } \\
\mathrm{Z}_{\mathrm{P3}}\end{array}$ & $\begin{array}{l}\text { Test } \\
\text { data } \\
\mathbf{Z}_{\mathbf{P 4}}\end{array}$ & $\begin{array}{l}\text { Tes } \\
\text { t } \\
\text { dat } \\
\text { a } \\
Z_{P 5}\end{array}$ \\
\hline $\begin{array}{l}\text { Extraction } \\
\text { process Bio } \\
\text { base stock } \\
(\%)\end{array}$ & $\begin{array}{l}70- \\
100\end{array}$ & 70 & 70 & 70 & 70 & 70 \\
\hline $\begin{array}{l}\text { Bio } \\
\text { additive } \\
(\%)\end{array}$ & $0-30$ & 30 & 30 & 30 & 30 & 30 \\
\hline $\begin{array}{l}\text { Temperatur } \\
\text { e }\left({ }^{0} \mathrm{C}\right)\end{array}$ & $\begin{array}{l}0- \\
150\end{array}$ & 120 & 120 & 120 & 120 & 120 \\
\hline $\begin{array}{l}\text { Blending } \\
\text { process } \\
\text { Density } \\
\left(\mathrm{kg} / \mathrm{m}^{3}\right)\end{array}$ & $\begin{array}{l}900- \\
950\end{array}$ & 920 & 920 & 922 & 923 & 923 \\
\hline $\begin{array}{l}\text { Flash point } \\
\left({ }^{0} \mathrm{C}\right)\end{array}$ & $\begin{array}{l}300- \\
350\end{array}$ & 331 & 328 & 329 & 328 & 330 \\
\hline $\begin{array}{l}\text { Viscosity at } \\
40^{\circ} \mathrm{C}\end{array}$ & $\begin{array}{l}35- \\
45\end{array}$ & 40 & 42 & 42 & 41 & 39 \\
\hline $\begin{array}{l}\text { Viscosity at } \\
100^{\circ} \mathrm{C}\end{array}$ & $\begin{array}{l}7.5- \\
8.5\end{array}$ & 8.1 & 8.2 & 8.3 & 8.2 & 8.0 \\
\hline $\begin{array}{l}\text { Characteriz } \\
\text { ation } \\
\text { Temperatur } \\
\text { e }\left({ }^{0} \mathrm{C}\right)\end{array}$ & $\begin{array}{l}-30- \\
250\end{array}$ & -20 & 40 & 100 & 160 & 220 \\
\hline $\begin{array}{l}\text { Characteriz } \\
\text { ation Time } \\
(\mathrm{min})\end{array}$ & $\begin{array}{l}0 \\
360\end{array}$ & 60 & 120 & 180 & 240 & 300 \\
\hline
\end{tabular}




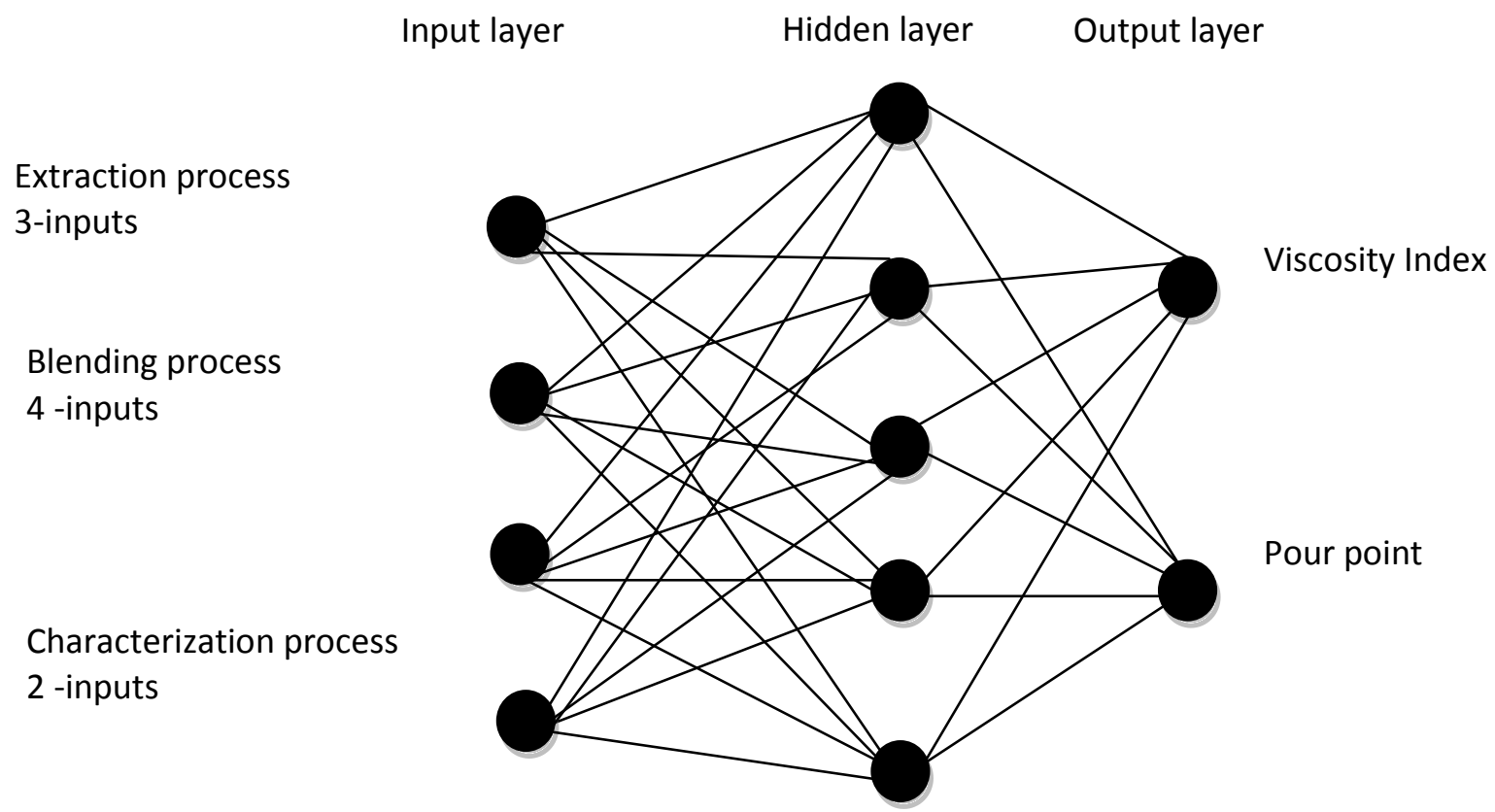

Fig 1: Neural network of Viscosity index and Pour point

\subsection{Output Data}

The viscosity index and pour point were considered as the outputs. The values of these output parameters correspond with the blend of bio base stock and bio additives samples as represented by ZE1 -ZE5 in Table 2.

Table 2: The Experimented Viscosity index and Pour

\begin{tabular}{|l|l|l|l|l|l|}
\hline $\begin{array}{l}\text { Output } \\
\text { Parameters }\end{array}$ & $Z_{\mathrm{E} 1}$ & $Z_{\mathrm{E} 2}$ & $\mathrm{Z}_{\mathrm{E} 3}$ & $\mathrm{Z}_{\mathrm{E} 4}$ & $\mathrm{Z}_{\mathrm{E} 5}$ \\
\hline Viscosity index & 192 & 192 & 194 & 193 & 192 \\
\hline Pour point & -21 & -20 & -23 & -22 & -21 \\
\hline
\end{tabular}

The best neural networks architecture and learning algorithm are unknown in advance, so a trial and error was used to find the best network characteristics for matching the particular input/output relationship. The following network architectures were investigated using MATLAB 7.9.0 (r 20096), (i) One layered network 9, [1], 1. 9, [5], 2. (ii) Two layered network $9,[4-3] 2,2.9,[5-5] 2,2$. (iii) Three layered network 9, [55-3]3, 2. 9, [6-5-4]3, 2 .

The above networks architectures were trained using the following algorithms: Levenberg-Marquardt [LM], Bayesian Regulation [BR]. The sigmoid function was used between the input and the hidden layers as shown in equation 1

$\mathrm{f}(\mathrm{x})=1 / 1+\mathrm{e}-\mathrm{x}$ -equation 1

and linear function $\{\mathrm{f}(\mathrm{x})=\mathrm{x}\}$ was used between the hidden and output layer.

Pre -processing of the inputs parameters were carried out before the neural network training. Bio base stocks and bio additives were presented to the network in acceptable proportional ratios to make one whole i.e. $100 \%$, while other parameters were presented in the range of minimum to maximum values. Using MATLAB Command 'Mapminmax', the matrix were processed by mapping row minimum and row maximum values using equation 2

$\mathrm{I}=1+($ Icurr $-\operatorname{Imax}) /(\operatorname{Imax}-\mathrm{Imin})$ -equation 2

Where Icurr $=$ Current input value, Imax $=$ Maximum input value and Imin $=$ Minimum input value.

\section{RESULTS AND DISCUSSION}

The neural model architecture shown as BR 9, [5], 2 was chosen for the prediction of Viscosity index and Pour point of some bio lubricants from selected bio plants, after series of training using different neural network architectures:
(i)One layered network
$9,[1]_{1}, 2$.
$9,[5]_{1}, 2$.
(ii)Two layered network $9,[4-3]_{2}, 2$.
$9,[5-5]_{2}, 2$.

(iii) Three layered network 9, [5-5-3 $]_{3}, 2 . \quad 9,[6-5-4]_{3}, 2$.

Training performance indicated values of regression $\mathrm{R}=$ 0.99983 and the overall performance of regression $R=0.9953$ for training validation and testing. The neural model architecture indicated as BR $9[5]_{1}, 2$ was chosen because it showed very good correlation for both the training $\left(\mathrm{R}^{2}=\right.$ $0.998)$ and testing $\left(R^{2}=0.9953\right)$ compared with other $B R$ architecture model as described in table 3 below.

Table 3: Summary of results of tested BR ANN Architecture

\begin{tabular}{|l|c|c|}
\hline $\begin{array}{l}\text { ANN } \\
\text { Architecture }\end{array}$ & $\begin{array}{l}\mathrm{R}^{2} \\
\text { Training }\end{array}$ & $\begin{array}{l}\mathrm{R}^{2} \\
\text { Testing }\end{array}$ \\
\hline BR 9, $[1]_{1}, 2$. & 0.601 & 0.513 \\
\hline BR 9, $[5]_{1}, 2$. & 0.998 & 0.995 \\
\hline BR 9, $[4-3]_{2}, 2$. & 0.819 & 0.800 \\
\hline BR 9, $[5-5]_{2,}$, & 0.845 & 0.832 \\
\hline
\end{tabular}




\begin{tabular}{|l|l|l|}
\hline BR 9, $[5-5-3]_{3}, 2$. & 0.864 & 0.849 \\
\hline BR 9, $[6-5-4]_{3}, 2$. & 0.901 & 0.863 \\
\hline
\end{tabular}

Table 4 below shows the values of the predicted Viscosity index and targeted (real) Viscosity index with their respective errors and characterization temperatures. It was observed that the neural network prediction of the Viscosity index showed good agreement with the targeted (real) Viscosity index with the network errors of $-0.003291,-0.005223,-0.005486$, $0.006719,-0.004843$. The slight disparity in the values could be attributed to errors in the data arising from poor experimental design, fault in equipment or miscalculation.

Table 4: Predicted and Real (Target) Viscosity Index with Network Errors and Temperature

\begin{tabular}{|c|c|l|c|}
\hline Predicted & $\begin{array}{l}\text { Real } \\
\text { (Target) }\end{array}$ & Network Errors & $\begin{array}{l}\text { Characterization } \\
\text { Temperature }\end{array}$ \\
\hline 191.9697 & 191.9394 & -0.003291 & $-30 \_20$ \\
\hline 191.9948 & 191.9896 & -0.005223 & $20 \_70$ \\
\hline 193.9945 & 193.9890 & -0.005486 & $70-120$ \\
\hline 192.9931 & 192.9866 & -0.006719 & $120-170$ \\
\hline 191.9951 & 191.9904 & -0.004843 & $170-220$ \\
\hline
\end{tabular}

Table 5 below shows the values of the predicted Pour point and targeted (real) Pour point with their respective network errors and characterization time. It was also observed that the neural network prediction of the Pour point showed good agreement with the targeted (real) Pour point with reasonable network errors of $-0.004662,-0.002953,-0.003248$, $0.002761,-0.003187$ between the predicted and the real values.

Table 5: Predicted and Real (Target) Pour point with Network Errors and characterization time

\begin{tabular}{|l|l|l|c|}
\hline Predicted & $\begin{array}{l}\text { Real } \\
\text { (Target) }\end{array}$ & $\begin{array}{l}\text { Network } \\
\text { Errors }\end{array}$ & $\begin{array}{l}\text { Characterization } \\
\text { time }\end{array}$ \\
\hline-20.9534 & -20.9068 & -0.004662 & $0-60$ \\
\hline-19.9970 & -19.9940 & -0.002953 & $60-120$ \\
\hline-22.9675 & -22.9643 & -0.003248 & $120-180$ \\
\hline-21.9972 & -21.9945 & -0.002761 & $180-240$ \\
\hline-20.9968 & -20.9936 & -0.003187 & $240-360$ \\
\hline
\end{tabular}

The quality of prediction of Viscosity index and Pour point of the blended products produced from bio base stock and bio additive were evaluated taking into cognizance the following points. (i) The quality of prediction of the Viscosity index against characterization temperature (ii) The quality of prediction of Pour point against characterization time.

The best result in prediction of Viscosity index and Pour point of the blended products produced have been shown by the neural model denoted as BR 955 2. This neural model was obtained by training of one layered neural network. $9,[5]_{1}, 2$. [four (4) inputs, five ( 5) neurons in the hidden layer and two (2) output] with Bayesian Regulation (BR) algorithm.

Table 4 showed comparison between the real (target) and predicted Viscosity index against characterization temperature. It was observed that Viscosity index slightly increased with increase in temperature for both the predicted and the real (target) values but the values were still within a particular range which shows that temperature has no serious effect on Viscosity index. According to Table 4 there was no further increase in Viscosity index beyond $120^{\circ} \mathrm{C}$ and predicted Viscosity index of 193.9945 at $120^{\circ} \mathrm{C}$ compared well with the values of $185-190$ given by [10]. This indicates that the neural model has performed well as reported by other researchers, [11], [9].

The prediction of change of Pour point of the blended products against characterization time is shown in Table 5. It was observed that both the predicted and real values of Pour point of the blended product increased with increase in the characterization time and thereafter remained constant before a decrease after an extended time. This is because characterization time increases as the temperature also increase and beyond a given temperature the pour point also decreases. This can be seen from the prediction of pour point of -20.9534 to -20.9968 as shown in Table 5. This is better than the value of $-18^{0} \mathrm{C}$ by [12]. This has clearly shown that the network prediction is reasonable.

\section{CONCLUSION}

The development of models related to prediction of Viscosity index and Pour point for blended product produced from bio base stock and bio additive was successful with reasonable network errors. An approach for modeling the influence of relevant factors such as Product extraction, blending and characterization has been suggested. It is shown that the computer based model provided by artificial neural networks may help in predicting the Viscosity index and Pour point of the various samples.

The best results in prediction of the Viscosity index and Pour point have been reached by simple neural model BR 9, 5, 2 . The developed neural model was able to predict the Viscosity index and Pour point of the different samples of the blended product from bio base stock and bio additives obtained in varying proportions.

\section{REFERENCES}

[1] Lansdown, A. 2004. Lubrication and Lubricant Selection, a practical guide ASME Press

[2] Mang, T. and Dresel, W. 2005. Lubricants and Lubrication. Weinhein Wiley-VCH.

[3] Hafizpour, H.R., Sanjari, M., and Simchi, A. 2009. "Analysis of the effect of reinforcement particles on compressibility of AL-SIC Composites powders using neural network model" Materials Design Vol 33 pp15181523

[4] Birbilis, N. Cavanaugh, M.K. Sudholz, A.D. Zhu, S.M. Ecston, M.A. and Gibson M.A. 2011. "A Combined neural network and mechanistic approach for the prediction of corrosion rate and yield strength of magnesium - rare earth alloys" Corrosion Science Vol 53 pp 701-782. 
[5] Kamrunnahar, M. and Urquidi- Macdonald, M. 2011. "Prediction of Corrosion behavior using neural network as a data mining tool" Corrosion Science Vol. 53 pp 961 967.

[6] Elaine, D.K. Ramon, S.C.P., Luiz, A. L., Yuri, C.S., Gabriel, P.D., Jose, L. 2009. "Artificial neural network corrosion modeling for metals in an equatorial climate". Corrosion Science vol 51 pp 2256-2278.

[7] Cottis, R.A. Qing, L.I. Owen, G. Gartland, S.J. Heliwell, I.A. and Turega, M. 1999. "Neural network methods for corrosion data reduction" Materials and design Vol. 20 pp169-178.

[8] Zhang, Z. Barkoula, N.M. Karger-Kocsisk, K. Friedrick, F. 2003. "Artificial neural network prediction on erosive wear of Polymers." Tribology international Vol 255 pp708-713

[9] Velten, K., Reinicke, R. and Friedrick, F. 2000. "Wear volume prediction with artificial neural network". Tribology International Vol 33 pp 731-736.

[10] Farng, L.O. 2003. Ashless Antiwear and Extreme Pressure Additives in lubricant additives chemistry and Applications (ed L.R. Rudnick) Marcel Dekker Inc. New York.

[11] Dragan, A. 2010. "Neural network prediction of brake friction material wear" Wear Vol. 268 pp 117-125.

[12] Randles, S.J. 1994 Formulation of Environmentally Acceptable Lubricants $49^{\mathrm{TH}}$ STLE Annual meeting Pittsburgh. 